or semi-erect, but as far as I could observe nearly all the teeth came into play. When on fishing excursions in the lagoon, the sharks which constantly carried off the bait, were often caught, and in order to extract the hook, a large log, constantly carried in the boats for this purpose, was threateningly presented to its face, and "of "course instantly seized and beld on to for as lone as it took to perform the operation of extraction. If, when the fish is quite recently dead, pressure be made on the angle of the jaw, it is easy to observe the action of the rows of teeth.

Kesala, Bantam, Java, July

HENRY O. FORBES

\section{A Lunar Rainbow}

LAsT evening, September 3, at 10.40, a lunar rainbow was visible at Llanfairfechan, in a north-west direction. The arc was continuous, and of a brilliant white light. It appeared to stretch across Anglesey from Beaumaris to Puffin Island. The bow did not last more than $2^{\prime}$ from the time it was first observed by us.

F. E. KITCHENER

Llanfairfechan, September 4

\section{A Habit of Cattle}

IN the colony of NataI the cattle have an extraordinary liking for bones. They will stand for hours with a bone in the mouth quietly munching, sucking, or perhaps more correctly speaking, levigating the bone with the tongue. I have not heard that cattle have the same habit in the other colonies of South Africa, but I have been told that cattle exhibit the same taste in some parts of South Australia.

In Natal there is, I believe, a scarcity of chalk and limestone in the geological formation. Will this fact account for the habit? Do the eattle lick bones in search of lime?

Can any of your readers account for this strange taste in cattle?

I may mention that horses and other herbivorous animals in Natal do not exhibit the same taste.

Delagoa Bay, July 20

\section{THE AUGUST PERSEIDS}

$\mathrm{T}$ HIS remarkable meteor shower recurring annually on August Io is looked for every year with increasing diligence. To Quetelet belongs the credit of having first (in 1835) ascertained the epoch of its maximum display, though the month of August had long been known as one in which there was an abundance of falling stars. As early as 1762 Muschenbroek, in his work on "Natural Philosophy," stated that, according to his own observations, there were more shooting stars in August than at any other period of the year, and his remark is perfectly true applied to the first half of that month, though it is questionable whether the last half of August will bear comparison with that of July, when meteors fall very plentifully, and constitute a periodical display of special note on the 27th-3Ist. Since Quetelet determined the date of the Perseids, they have been expected every year with great interest, and from the time that Heis first began systematically to register the paths of meteors (nearly half a century ago) to the present day, observers have continued to record the successive apparitions of this prominent star-shower, so that multitudes of its meteors are now accumulated in the catalogues of British and foreign astronomers.

These Perseids appear to have belonged to our system at a very remote epoch, and to have been observed in considerable intensity as far back as the ninth century of our era. They form a continuous ring or zone of particles. The stream may vary in richness, that is to say, the particles may be very unequally distributed along the orbit, but it seems unbroken and manifests itself every year with more or less intensity from its accustomed point yielding many bright meteors of great swiftness, and almost invariably accompanied by phosphorescent streaks. It was from careful observations of the Perseids that Schiaparelli, in I866, was led to his theory of the connec- tion or identity of comets and meteors, and the first orbital coincidence found was that of the Perseids with Comet III. 1862, which seems to have been merely the nucleus or condensation of the particles forming this remarkable rneteor system.

The annual returns of this shower as observed and described by various observers, when compared together, show that in certain years the display is exceptionally brilliant ; in others it is far less imposing. Eduard Heis, at Muinster, counted I55 meteors per hour on August Io, 1863 , yet on the same night in 1867 the figures had fallen to 24 per hour. He gives the following as the horary numbers derived from observations between rob. and I2h. at several stations in Germany on August ro in different years :-

\begin{tabular}{|c|c|c|c|c|c|}
\hline Year. & Station. & $\begin{array}{c}\text { Hourly } \\
\text { number. }\end{array}$ & Year. & Station. & $\begin{array}{l}\text { Hourly } \\
\text { number }\end{array}$ \\
\hline $184 \mathrm{I}$ & Aachen ... & 47 & $\mathrm{I} 863$. & Muinster & \\
\hline 1842 & Aachen ... & 60 & 1863. & Gaesdonck & $\ldots 215$ \\
\hline 1847 & Aachen ... & 55 & $x 863$ & Peckeloh & $\ldots \operatorname{rog}$ \\
\hline 850 & Aachen ... & $\ldots$ & 1864. & Gaesdonck & ... Io \\
\hline 85 & Münster ... & $\ldots$ & 1864. & Rom $\quad \ldots$ & \\
\hline 35 & Muinster ... & $\ldots$ & ×867... & Muinster & $\ldots$ \\
\hline 85 & M & 88 & 1867. & Peckeloh & \\
\hline $36 r$ & & $\ldots \quad 7^{8}$ & $1867 .$. & Papenburg & \\
\hline 86 & Gaesdonck & $\ldots 102$ & $187 \mathrm{r} .$. & Peckeloh & \\
\hline & Peckeloh & $\ldots .102$ & 1872. & Rom $\quad \ldots$ & $\ldots$ \\
\hline 86 & Rom & $\ldots \quad 89$ & 1874. & Rom & ... Iro \\
\hline
\end{tabular}

Maximum in 1863 , minimum in 1867 and 1850 . There were also many Perseids in 1839 , when Heis counted 160 per hour. The displays of 1863 and $187 \mathrm{I}$ were of considerable intensity. On August Io, 1863, 9h. to $13 \frac{1}{4}$ h., Heis, assisted by several other observers at Münster, registered the paths of 602 shooting stars, and at Gaesdonck on the same night, 563 were recorded between 9 h. $17 \mathrm{~m}$. and I $2 \mathrm{~h} .9 \mathrm{~m}$. It may be mentioned as a curious anomaly, showing how much "personal equation" may have to do with the estimation of meteor magnitudes, that at the two stations referred to, the meteors were classified as follows :-

\begin{tabular}{lrrrrrrrrrr} 
& \multicolumn{3}{c}{ 1st mag. } & 2nd mag. & $3-6$ mag. & $\begin{array}{c}\text { Number } \\
\text { with } \\
\text { streaks. }\end{array}$ & $\begin{array}{c}\text { Total. } \\
\text { meteors. }\end{array}$ \\
Münster & $\ldots$ & 224 & $\ldots$ & 226 & $\ldots$ & 151 & $\ldots$ & 300 & $\ldots$ & 601 \\
Graesdonck & $\ldots$ & 37 & $\ldots$ & 84 & $\ldots$ & 442 & $\ldots$ & 158 & $\ldots$ & 563
\end{tabular}

The Münster observers evidently overrated the magnitudes to an enormous degree.

The display of $187 \mathrm{r}$, though less decided than in 1863 , was still a very rich return of these meteors. On August Io in that year, Signor Bassani, at Cosenza, in Italy, assisted by Signor Scrivani, counted 674 meteors from gh. to I6h., and at Boston, Mass., Messrs. Sawyer and Stephens, watching the sky from Ioh. to $15 \mathrm{~h}$. on the same night, recorded 567 meteors. Since that year the displays have not been of special brilliancy, though on August 10, 1874, 28r meteors were counted at Bristol by the writer in a watch of four hours, from 10.45 , to 14.45 , and on August 10, 1877, 354 meteors were seen in the five hours, from 9.30 to 14.30 , giving an hourly number (for one observer) in both years of about seventy.

Dr. Phipson suggested ${ }^{1}$ it was to be inferred from the observations that a maximum occurred at intervals of eight years. There had been considerable showers in 1839,1847 , and I863, and he pointed out that a similar manifestation was due in $187 \mathrm{r}$. In that year we had, as already described, an unusually numerous return of these meteors, and if the suspected periodicity held good, there would be another rich shower in 1879 . Perhaps on that account the Perseids of the present year were anticipated with a little more than ordinary interest, but the night of August Io was generally overcast in England (though at several stations a few meteors were discerned through breaks in the clouds), and thus the chief display has escaped us, though we may yet receive favourable reports

\footnotetext{
${ }^{1}$ See his "Meteors, Aerolites, and Falling Stars," p. 159.
} 